PROCEEDINGS OF THE SIXTH INTERNATIONAL SEMINAR ON

"Recent Research and Design Progress in Aeronautical

Engineering and its Influence on Education “ - Riga, Latvia

\title{
ANALYSIS OF CALCULATION RESULTS OF LIFT AND DRAG FORCES FOR SEVERAL WINGS USING NONLINEAR SECTION DATA
}

\author{
E. Pakalnis, E. Lasauskas, J. Stankūnas
}

Antanas Gustaitis Aviation Institute of Vilnius Gediminas Technical University, Rodūnès 30, LT-02187, Vilnius-38, Lithuania,E-mail: egidijus.pakalnis@tetrapak.com,edulas@ai.vtu.lt,jnst@ai.vtu.lt Received 1701 2005, accepted 17032005

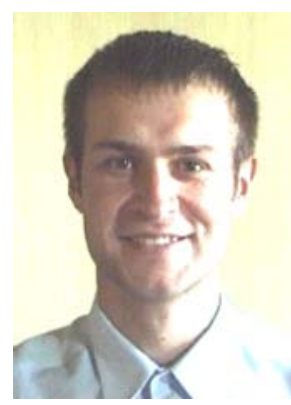

Egidijus PAKALNIS was born in 1974, in Biržai. In 1996 graduated Aviation Institute of Vilnius Gediminas Technical University. In 1998 received master's degree of aviation mechanics. From 1997 to 2002 worked in Antanas Gustaitis Aviation Institute as chief engineer. At present doctoral student of Vilnius Gediminas Technical University. Interest of research - low speed nonlinear aerodynamics. Author and co-author of eight scientific articles.

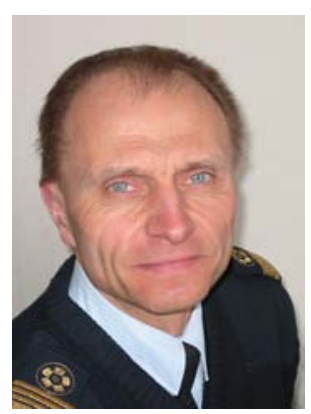

Eduardas LASAUSKAS, Assoc Prof Dr

Date and place of birth: 1952 in Shvenchioneliai, Lithuania.

Education: 1976 - Kazan Aviation Institute, an Aeronautical Mechanical Engineer.

Affiliations and functions: Since 1973 - Prienai factory "Sportinè aviacija"; since 1998 - Research assistant in Aviation Mechanic Department of Antanas Gustaitis Aviation institute of Vilnius Gediminas Technical University; 2000 - scientific degree of Doctor; since 2001 - Associate Professor and a Head of the Aviation Mechanics Department.

Experience: design of sailplanes: LAK-5, LAK-9, LAK-9M, LAK-10 LAK-11, LAK-12, LAK-12E, LAK-15, LAK17, LAK-17A, LAK-19 and LAK-20. He leaded the design of the test bed SL-2P for the wing section testing in free flight. He designed the wing sections for the sailplanes LAK 17A, LAK-19 and LAK-20; he has a glider pilot licence, his flight experience with sailplanes is over 1300 hours.

Teaching: Aerodynamics and Flight Dynamics.

Professional memberships: Member of International Scientific and Technical Organisation for Soaring Flight OSTIV. Research interests: Low speed aerodynamics and Flight mechanics. He is the author of 14 scientific articles.

Present position: Head of the Aviation Mechanics Department at Antanas Gustaitis Aviation Institute of Vilnius Gediminas Technical University; Rodūnès k. 30, LT - 2038 Vilnius, Lithuania; Tel. 37052739 039, fax. 37052329 321, e-mail: avinst@ai.vtu.lt

Jonas STANKŪNAS, Prof Dr Habil

Date and place of birth: 1949 in Pakenè, Rokiškis Distr., Lithuania.

Education: 1970 - Krivoj Rog Civil Aviation School, Ukraine; 1976 - Faculty of Automation at Vilnius Institute of Civil Engineering; 1981 - post - graduated studies at Vilnius Institute of Civil Engineering.

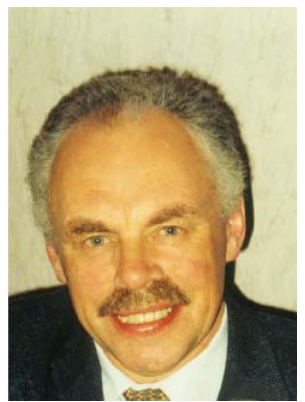

Affiliations and Functions: 1970 - 1972 - Aviation Technician, Vilnius Joint Aviation Platoon; 1972 - 1975 Expert, Radio Apparatus Technology Dept., 1975 - 1978 - Sr. Eng., Sector of Science Research; 1982 - 1987 - Head of Science Laboratory of Slow Wave and Deflecting Systems, Vilnius Institute of Civil Engineering; 1988 - 1993 Assoc Prof, Radio Apparatus Technology Department, Vilnius Technical University (formerly, Vilnius Civil Eng. Institute) and Kaunas University of Technology (formerly, Kaunas Polytechnic. Institute.). Since 1993 - Director of Antanas Gustaitis Aviation Institute (AGAI) of Vilnius Gediminas Technical University; 1993 - 1995 - Assoc Prof, 1995 - Habilitated Doctor; 1995 - 1997 - Prof, Air Traffic Control Department (AGAI); since 1997 - Prof, Avionics Department (AGAI); since 2002 - Director of the Defense Technology Center of Vilnius Gediminas Technical University.

Awards: Laureate of Lithuanian Award in Technology Sciences, 1997.

Publications: Author or co-author of 104 scientific articles, 2 monographs, 28 reports, 97 scientific reports, and 9 education methodological publications.

Inventions: Author or co-author of 14 inventions.

Training: Advancement training in Great Britain, Canada and Sweden. $370 \quad 52329$ 321, e-mail: jonas.stankunas@ai.vtu.lt; avinst@ai.vtu.lt; jnst@ai.vtu.lt

Abstract. Calculation results for 11 different finite span wings are presented. Calculations were made by a combination of a numerical solution of lifting line theory with a technique developed to evaluate nonlinear section lift data. Aerodynamic coefficients for these wings are compared to the research results of other authors and to experimental data.

Key words: lift, drag, wing, non-linear aerodynamics. 


\section{Introduction}

Aerodynamic coefficients were determined for 11 different finite span wings. Comparisons to experimental data and to with results of calculations of other authors are presented. The calculations were made by a combination of the Vortex Step Method with a technique developed to evaluate nonlinear section lift data. Results include various flow conditions from $\mathrm{Re}=4000$ for a straight plate to $\mathrm{Re}=2,7 \times 10^{6}$ for a swept wing. Wings were chosen according to available experimental data.

\section{Review of methods using non-linear section lift data for calculation of lift and drag force along a wing span}

Prandtl's Lifting Line Theory is the basis for most methods used to calculate change of lifting force of flat, low sweep angle and moderate and high aspect ratio wings. Tani developed the first successful technique in 1934 for handling nonlinear section lift-curve slopes in the formulation of Prandtl's Lifting Line Theory [17]. This method was made popular by the 1947 NACA (National Advisory Committee for Aeronautics) report of Sivells and Neely that provides a detailed description of the method for unswept wings with arbitrary planform and airfoil lift-curve slopes [15]. They apply this method for analysis of wings up to stall, i.e., until a wing angle of attack at any section on the wing has $C_{1}$ equal to $C_{\text {lmax }}$.

Numerical solutions of Prandtl's Lifting Line Theory were also developed and are still in use. The most well known works using these methods are the research of McCormick and Anderson et al. [8, 1]. The method is also reflected in resent research of W. F. Phillips and D. O. Snyder [13].

The research of Mutteperl] and Weisinger [19] made a base for the so-called Finite-Step Method or Vortex Step Method, which also was developed from Prandtl's Lifting Line Theory. Later Campbell and Blackwell simplified their method $[10,4,3]$. These methods presented the first attempts to couple sectional (twodimensional) viscous results with inviscid wing (threedimensional) theory. The most resent research reflecting their work has been made by Barnes J.P. [2]. He presents the Semi-Empirical Vortex Step Method, which includes empirical adjustments in lifting line position and shape.

Piszkin and Levinsky] developed a nonlinear liftingline method based in part on the iterative method originally conceived by Tani [14, 17]. Their method differs from Prandtl's classical LLT in the implementation of the boundary condition. Tseng and Lan developed an entirely different approach to the use of nonlinear section data [18]. In their method, the reduction at any given wing section is determined by the difference between the potential flow solution and the viscous $C_{1}$ from the nonlinear section $\mathrm{C}_{1}-\alpha$ curve.

In all methods using nonlinear section data the, main objective is that for the final solution of the threedimensional flow, the $\Gamma$ distribution across the span is consistent with the distribution of the effective $\alpha$ for each section, and the $C_{1}$ and $C_{m}$ for each section is consistent with the effective $\alpha$ for that section and the section $\mathrm{C}_{1}-\alpha$ and $\mathrm{C}_{\mathrm{m}}-\alpha$ data. Mukherjee R., Gopalarathnam A., and Kim S W. [9] achieve that condition by finding the effective reduction in the camber distribution for each section along the span.

Another possibility to take into account is the nonlinear section data in wing calculation presented in the research of K. Jacob [6]. His method combines an inviscid 3d-lifting surface theory with a 2d-airfoil theory that includes boundary layer calculations and a displacement model for rear separation

In this research the vortex step method, which differs from the methods mentioned above by the nonlinear section data implementation technique, was used. Here an idea of E. Lasauskas was developed into a separate method for wing lift and drag force calculation using nonlinear section characteristics [7].

\section{Model of a finite wing}

The wing model used is described in reference [11]. The method combines numerical solution of lifting line theory and a special approach to evaluate nonlinear section lift data. The iterative procedure allows wing lift at critical and post critical angles of attack to be predicted for the wings with moderate sweep and high aspect ratios.

\section{Results}

Figures 1 to 4 present calculation results of a rectangular flat plate of aspect ratio three at two different Reynolds numbers. Experimental results, presented in reference, were used as a section data [12]. These results were obtained in a low-speed, low-turbulence wind tunnel with a test section of $61 \times 61 \mathrm{~cm}$. Aluminium end plates were mounted in the test section. All wings tested were held at quarter-chord point, and a streamlined covering covered the sting. The gaps between the wing and the end plates were adjusted to approximately $0.8 \mathrm{~mm}$. Uncertainty in the angle of attack was determined to be of $0.2-0.3$ deg and $6 \%$ for $C_{L}$ and $C_{D}$.

Figures 1 and 2 present lift and drag for a rectangular wing of a flat plate at Reynolds number 8000 . Here it could be found that calculated curve presents the effect of finite wingspan compared to two-dimensional case. The results obtained are very close to the experimental results presented in ref. [12]. 


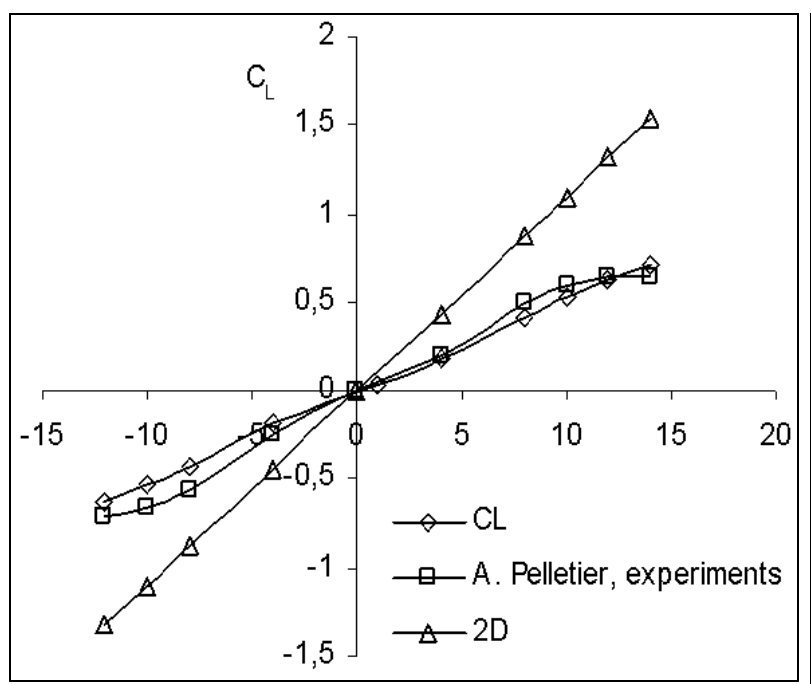

Fig 1. Lift coefficient of a flat plate rectangular wing of aspect ratio 3, at $R e=80000$. For calculation, section experimental results were used

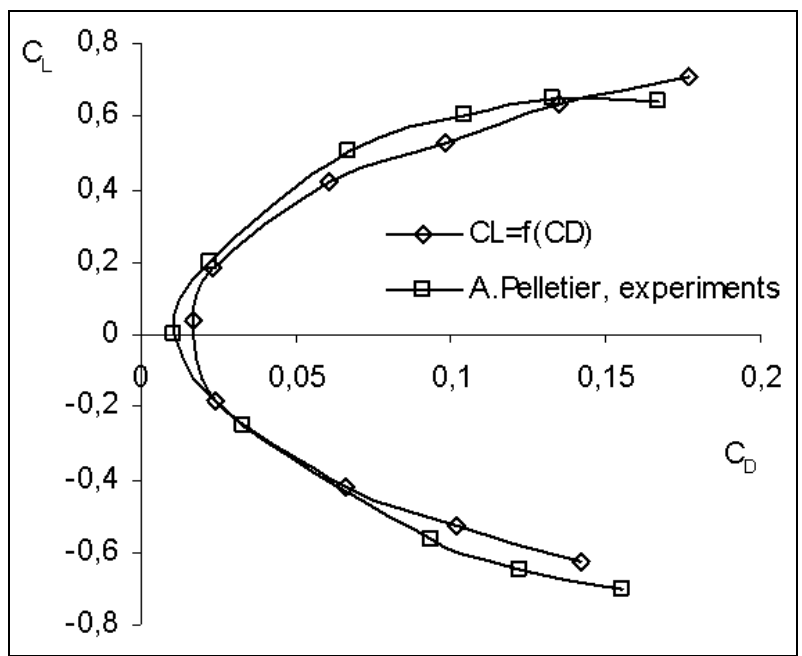

Fig 2. Lift-drag characteristics for a flat plate rectangular wing with aspect ratio 3 at $\mathrm{Re}=80000$. For calculation, section experimental results were used

Figures 3 and 4 present the results for the same wing at Reynolds number 14000 . It should be mentioned that the method itself does not account for the effect of the Reynolds number on the calculated wing characteristics. Here the change in the Reynolds number is evaluated in the $2 \mathrm{D}$ (sectional) characteristics, what means that a wing could be calculated for any Reynolds number for which $2 \mathrm{D}$ data is available. Compared to the results at $\mathrm{Re}=8000$, bigger differences are noticed between calculated and experimental results. However, the lift curve slope over 5 degrees of angle of attack is still very close.

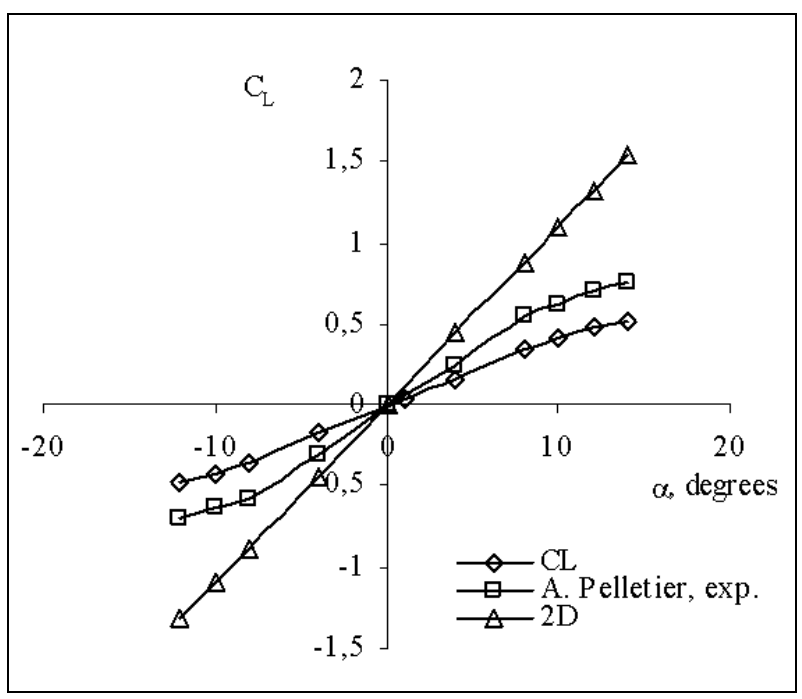

Fig 3. Lift coefficient of a rectangular wing of aspect ratio 3 at $\mathrm{Re}=140000$. For calculation, section experimental results were used

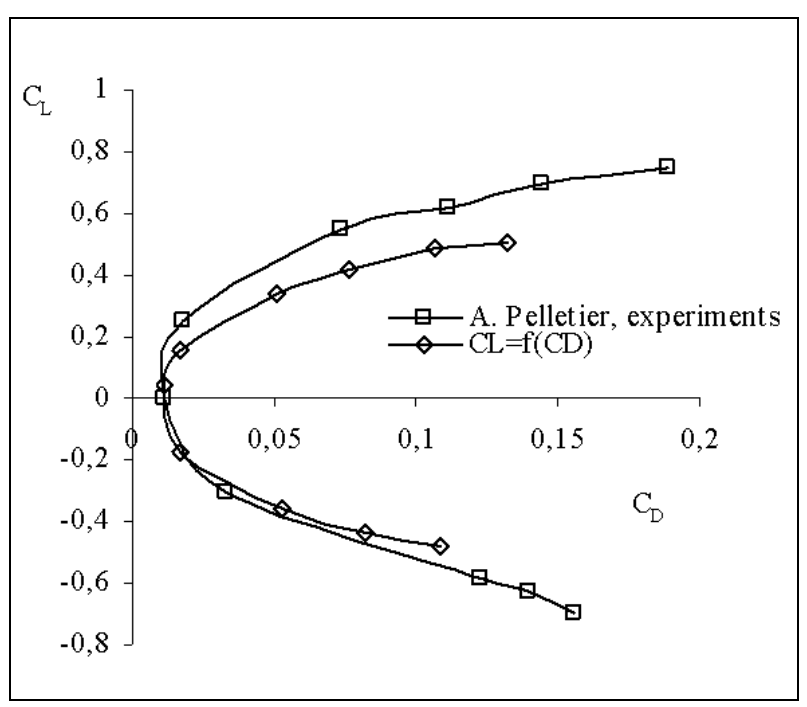

Fig 4. Lift-drag characteristics for a rectangular wing with aspect ratio 3 at $R e=140000$. For calculation, section experimental results were used

The following Figures 5-8 present another calculation attempt for a rectangular wing at ultra-low Reynolds numbers. Results are presented for several airfoils used for a wing of aspect ratio 7.25. Since experimental results were not available for such airfoils at $\mathrm{Re}=4000$, section calculation results were made by means of X-FOIL [5]. As can be seen from the figures, calculation results are quite far from the experimental results, which are presented in ref. [16]. 


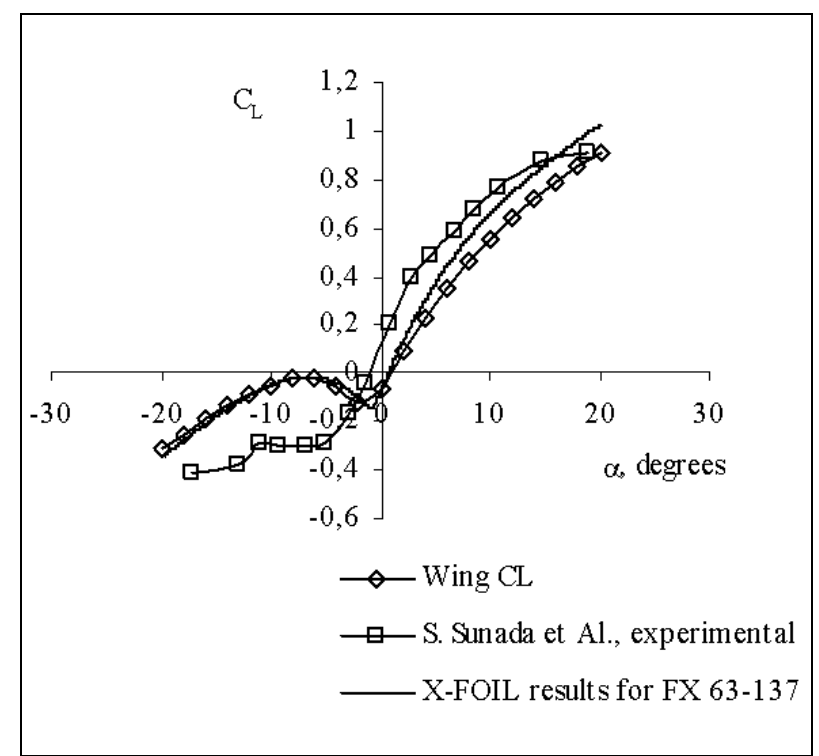

Fig 5. Lift coefficient of FX 63-137 rectangular wing $A R=7.25$ at $R e=4000$. X-FOIL calculation results were used as $2 \mathrm{D}$ section data

Such a situation was expected and is explained by the possibilities of X-FOIL. For such low Reynolds numbers X-FOIL cannot give suitable section characteristics.

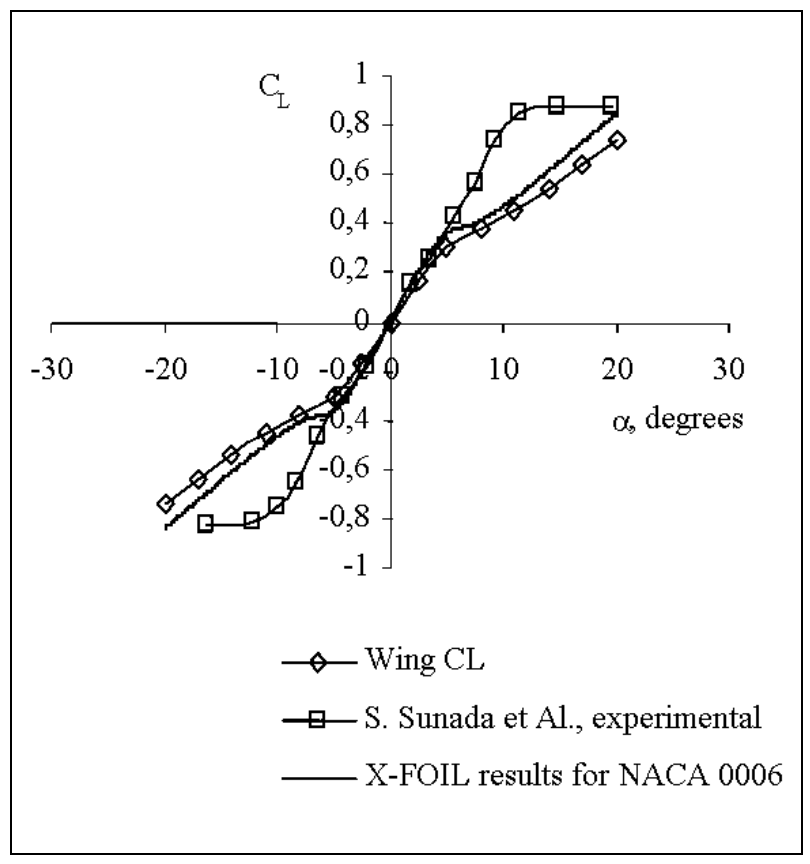

Fig 6. Lift coefficient of NACA 0006 rectangular wing with $\mathrm{AR}=7.25$ at $\mathrm{Re}=4000$. $\mathrm{X}$-FOIL calculation results were used as $2 \mathrm{D}$ section data

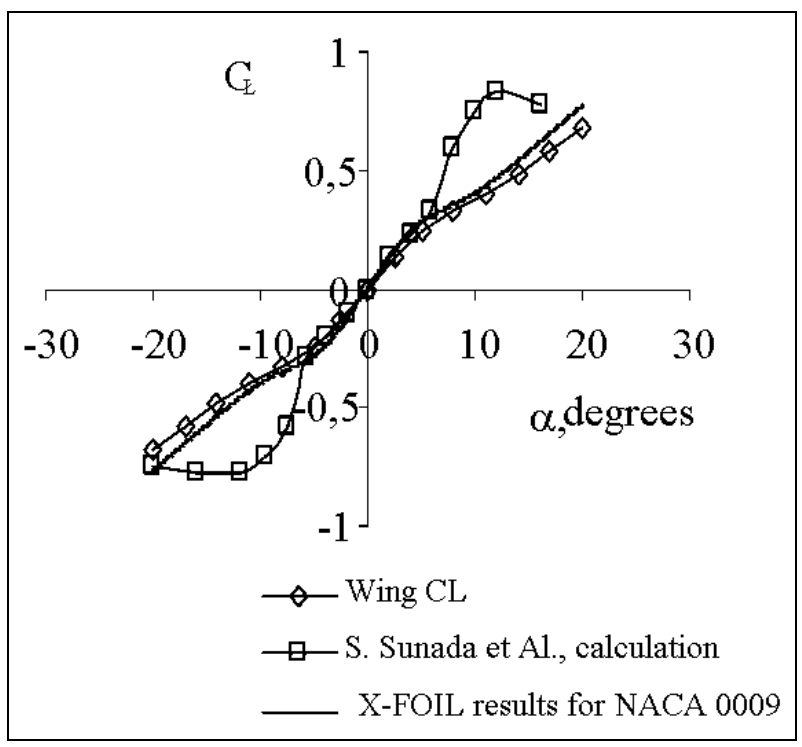

Fig 7. Lift coefficient of NACA 0009 rectangular wing with $\mathrm{AR}=7,25$ at $\mathrm{Re}=4000$. $\mathrm{X}$-FOIL calculation results were used as 2D section data

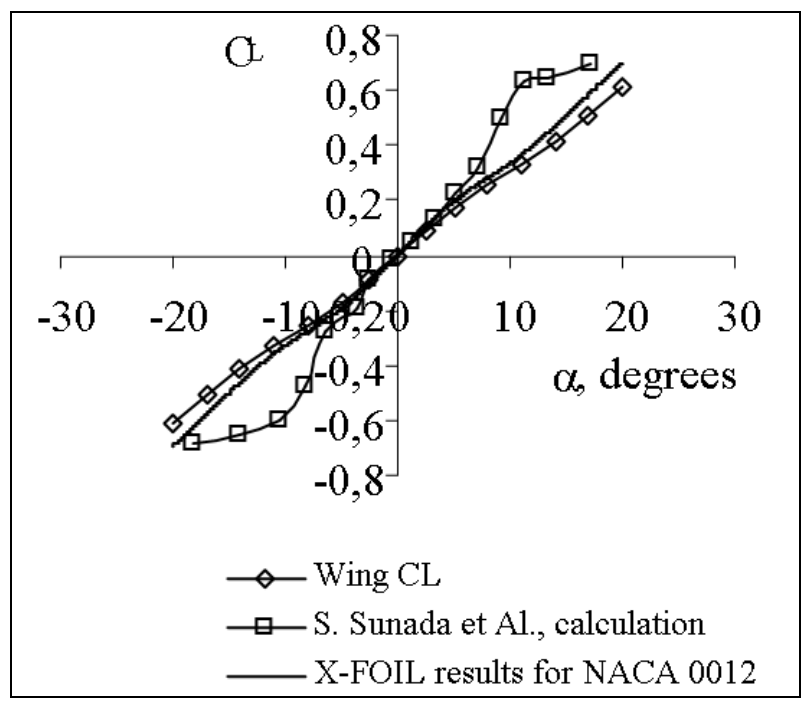

Fig 8. Lift coefficient of NACA 0012 rectangular wing with $\mathrm{AR}=7.25$ at $\mathrm{Re}=4000$. $\mathrm{X}$-FOIL calculation results were used as $2 \mathrm{D}$ section data

The results presented above make a proposal for more thorough research in the application of the method in the area of low Reynolds numbers. Due to lack of experimental data, it is not available at present time.

Figure 9 presents other calculation results for a rectangular wing with the use of X-FOIL sectional data. Here the results are compared with the results found by $\mathrm{K}$. Jacob and with experimental results [6]. 


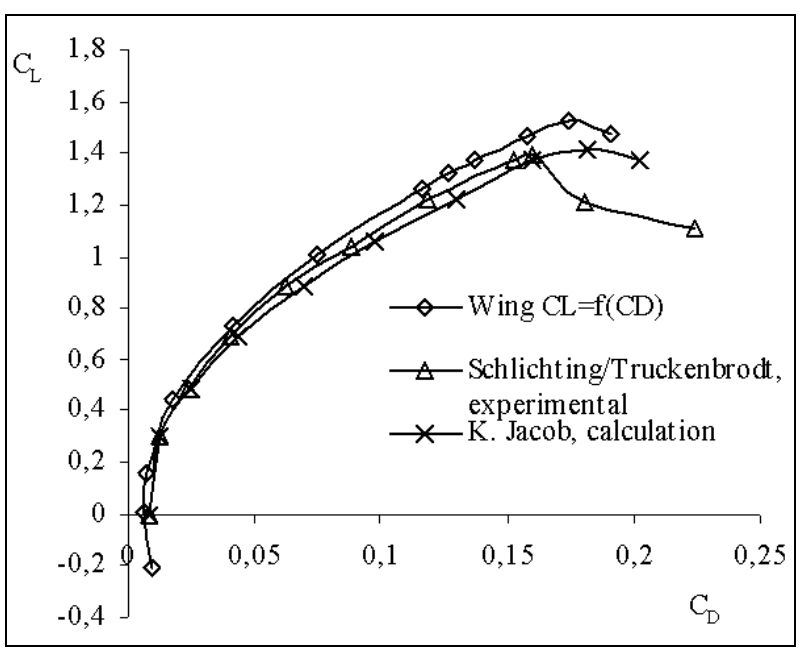

Fig 9. Lift-drag characteristics for a NACA 2412 rectangular wing with $\mathrm{AR}=5$ at $\mathrm{Re}=2.7 \times 106$. X-FOIL calculation results were used as $2 \mathrm{D}$ section data

As seen in Figure 9, there is good agreement between calculated and experimental results up to $\mathrm{C}_{\mathrm{Lmax}}$, but beyond it the experiments show a rapid decrease in lift. As this airfoil at calculated conditions develops a short bubble near the nose, this may be caused by the disappearance of the bubble [6]. Comparing the calculation results it is evident that the calculated lift curve slope is slightly higher than that obtained by $\mathrm{K}$. Jacob, which results in higher $\mathrm{C}_{\mathrm{Lmax}}$. As previous research shows, the problem is in the different section data used [11]. K. Jacob used experimental section data whereas XFOIL results were used in the present research. With the same source of section data, both methods present very close results. Such a situation can be noticed in figures 10 and 11, where the same experimental data were used by both methods.

Figure 11 presents the wing sweep evaluation results. Here calculation results for non-tapered NACA 4415 wing with $20 \mathrm{deg}$. of sweep back are presented. Close agreement with K. Jacob's results should be noticed.

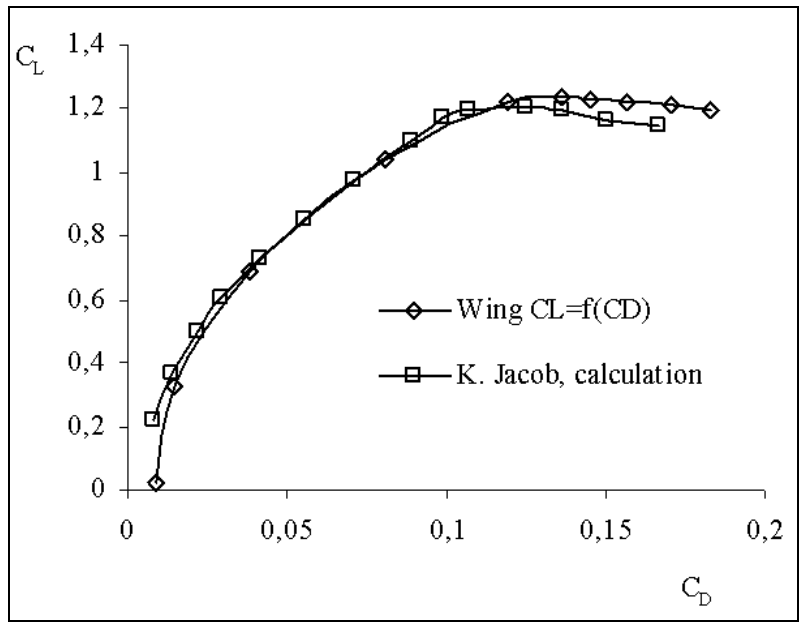

Fig 10. Lift-drag characteristics for a NACA 4415 rectangular wing with $\mathrm{AR}=6.2$ at $\mathrm{Re}=2.1 \times 106$. Experimental results were used as $2 \mathrm{D}$ section data
For the clarity here the difference from Klaus Jacob's method should be explained. Jacob [6] uses the following, which is different from that one used in the present method, procedure to calculate the effective angle of attack [11].

Induced flow angles for each wing section are computed with 3-d lifting surface theory. Effective angle of attack is determined in that way:

$$
\alpha_{e}=\alpha_{g}-\Delta \alpha
$$

Here:

$$
\begin{aligned}
& \Delta \alpha=F \cdot \Delta \alpha^{* *}+(1-F) \Delta \alpha^{*} ; \mathrm{F}=0.33 \\
& \Delta \alpha^{*}=\alpha^{*}-\left(\alpha^{*}\right)_{2-d} \\
& \Delta \alpha^{* *}=\alpha^{* *}-\left(\alpha^{* *}\right)_{2-d}
\end{aligned}
$$

Whereas induced angles of attack of the 3-d flow $\alpha^{*} \quad$ and $\alpha^{* *}$ are calculated from the system of linear equations based on the 3-d lifting surface theory, 2-d angles of attack are calculated in the following manner:

$$
\begin{aligned}
& \left(\alpha^{*}\right)_{2-d}=\left(C_{l}-C_{m}\right) / 2 \pi ; \\
& \left(\alpha^{* *}\right)_{2-d}=\left(C_{l}+8 C_{m}\right) / 2 \pi
\end{aligned}
$$

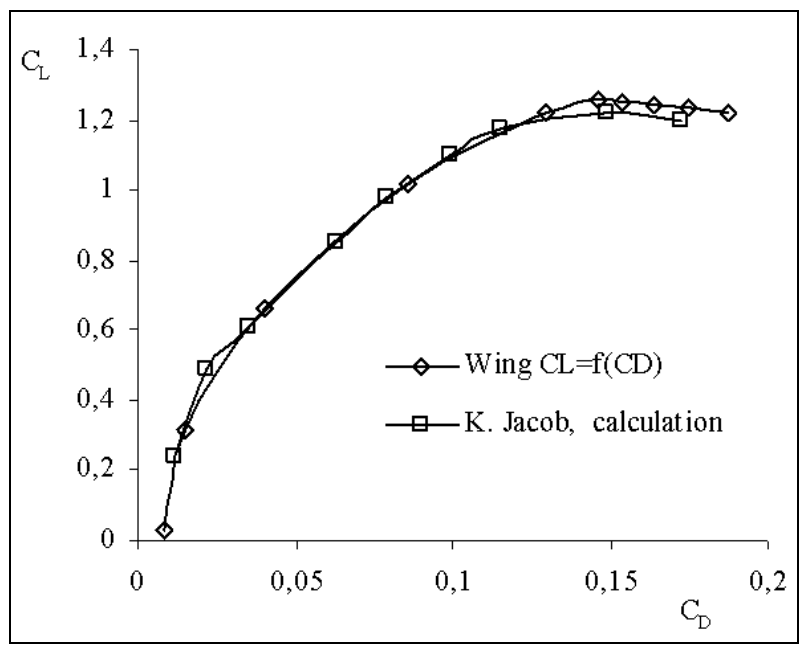

Fig 11. Lift-drag characteristics for a NACA 4415 not tapered swept wing ( 20 deg.) with $\mathrm{AR}=6.2$ at $\mathrm{Re}=2.1 \times 106$.

Experimental airfoil results were used as 2D section data

\section{Conclusions}

1. Despite some results obtained for a flat plate at very low Reynolds numbers, the limits of the calculation method used depends on the availability of reliable section data.

2. Low Reynolds number experimental data is needed in order to evaluate the capabilities of the method at a very low Reynolds numbers.

3. For the moderate and high aspect ratios of rectangular wings the method provides results that 
agree with the calculation results of $\mathrm{K}$. Jacob and with experimental results.

4. Agreement with Jacob's results appears in the calculation of a sweptback wing, but comparison with experimental results is needed in order to evaluate the reliability of such results.

\section{References}

1. Anderson J.D., Corda S., Van Wie, D.M. Numerical Lifting-Line Theory Applied to Drooped LeadingEdge Wings Below and Above Stall // Journal of Aircraft. - 1980. - Vol 17, No 12. - P. 898-904.

2. Barnes J P. Semi-Empirical Vortex Step Method for the lift and induced drag loading of 2D and 3D Wings // SAE Paper / Society of Automotive Engineers. 1997 Oct. - No 975559.

3. Blackwell J.A. A Finite-Step Method for Calculation of Theoretical Load Distributions for Arbitrary Lifting-Surface Arrangements at Subsonic Speeds // NASA TN D-5335. - 1969 July.

4. Campbell G.S. A Finite-Step Method for the Calculation of Span Loadings of Unusual Plan Forms / NACA RM L50L13. - 1951.

5. Drela M. XFOIL: An analysis and Design System for Low Reynolds Number Airfoils // Low Reynolds Number Aerodynamics. - New York: SpringerVerlag, 1989. - P. 1-12.

6. Jacob K. Computation of the Flow around Wings with Rear Separation // Journal of aircraft. -1984. Vol 21. - P. 97-98.

7. Lasauskas E., Pakalnis E., Stankunas J. A System of Nonlinear Equations for Wing Lift Calculation // Aviation. - Vilnius: Technika, 2002. - Vol 6. - P. 5054.

8. McCormick B.W. The lifting-Line Model, Aerodynamics, Aeronautics and Flight Mechanics. New York: Wiley, 1995. - Ed. 2. - P. 112-119.

9. Mukherjee R., Gopalarathnam A., Kim S.W. An Iterative decambering Approach for Post-Stall prediction of Wing Characteristics Using Known Section Data: $41^{\text {st }}$ AIAA Aerospace Sciences Meeting,
January 6-9, 2003/Reno, Nevada, AIAA. - 2003. P. 1097.

10. Mutteperl W. The Calculation of Span Load Distributions on Swept-Back Wings / NACA TN 834. - 1941 Dec.

11. Pakalnis E., Lasauskas E, Stankūnas J. Method to Evaluate Nonlinear Effect in Calculation of a Finite Span Wing // Transport and Engineering. Aviation transport. Scientific proceedings of Riga Technical University. - 2003. - Vol. 7.

12. Pelletier A. Muller T. Low Reynolds Number Aerodynamics of Low-Aspect-Ratio Thin/Flat/Cambered-Plate Wings // Journal of Aircraft. - 2000. - Vol 37, No 5, September-October.

13. Phillips W.F., Snyder D.O. Modern Adaptation of Prandtl's Classic Lifting-Line Theory // Journal of Aircraft. - 2000. - Vol 37, No 4. - P. 662-670.

14. Piszkin S.T., Levinsky E.S. Nonlinear Lifting Line Theory for Predicting Stalling Instabilities on Wings of Moderate Aspect Ratio / Tech. Rep., General Dynamics Convair Report CASD-NSC-76-001. 1976 June.

15. Sivells J.C., Neely R.H. Method for Calculating Wing Characteristics by Lifting-Line Theory Using Nonlinear Section Lift Data / NACA TN. - 1947 April. - No 1269.

16. Sunada S., Yasuda T., Yasuda K. et al. Comparison of Wing Characteristics at an Ultralow Reynolds Number // Journal of Aircraft. - 2002 March-April. Vol 39, No 2.

17. Tani I. A Simple Method of Calculating the Induced Velocity of a Monoplane Wing / Rep. Aero. Res. Inst., Tokyo Imperial University. - 1934 August. - No 111 (Vol 9, 3)

18. Tseng J.B., Lan C.E. Calculation of Aerodynamic Characteristics of Airplane Configurations at High Angles of Attack / NASA CR 4182. - 1988.

19. Weisinger J. The lift distribution of Swept-Back wings / NACA TM 1120. - 1947 March. 